\title{
Protein analysis of the spermatophore reveals diverse compositions in both the ampulla and the spermatophylax in a bushcricket
}

\author{
GER L I D U.C. L E H M N N ${ }^{1} \mathbb{D}$, K A R O L A L E M A N N ${ }^{2}$, \\ B OR IS NEUMA N N ${ }^{2}$, A R N W. LEHMA N N ${ }^{3}$, \\ CHR I T I A N S HELER ${ }^{2}$ and PETER R. J U N G L U T ${ }^{4}$ \\ ${ }^{1}$ Department of Biology, Humboldt University Berlin, Berlin, Germany, ${ }^{2}$ Proteome Factory AG, Berlin, Germany, ${ }^{3}$ Stahnsdorf, \\ Germany and ${ }^{4}$ Core Facility Protein Analyses, Max Planck Institute for Infection Biology, Berlin, Germany
}

\begin{abstract}
Nuptial gifts are male mating investments, which, in bushcrickets, comprise the sperm-containing ampulla and the attached spermatophylax. The functions of the spermatophylax are to deter females from premature removal of the sperm-containing ampulla, which is a nutrient resource for females, as well as a source of compounds that influence female behaviour to increase male evolutionary fitness. Placing these functions into a proteomic perspective, we analyze the protein composition of nuptial gifts from male Poecilimon ampliatus (BRUNNER von WATTENWYL, 1878) bushcrickets using large two-dimensional gel electrophoresis coupled with nano-liquid chromatography-electrospray ionization mass spectrometry and de novo sequencing. We separate the proteins with high resolution and detect approximately 600 protein spots in the seminal fluid (ampulla) and 300 in the spermatophylax. There is only a small fraction of overlap in protein spots, whereas the majority differ between the two compartments. As a result of the lack of a sequenced genome and protein data for this non-model insect, we are unable to identify the proteins. We discuss the diversity of proteins, as well as their size range, in light of potential protein costs and potential functions.
\end{abstract}

Key words. Bushcricket, evolutionary proteomics, mating effort, nuptial gifts, Poecilimon, spermatophore.

\section{Introduction}

The transfer of gametes between the sexes is essential for mating in animals. However, differential investment of the sexes into mating and reproduction leads to unbalanced costs and benefits. Males generally invest less, although some species contribute more by offering costly nuptial gifts to the female (Lewis etal., 2014). Nuptial gifts are provided by a large variety of animals and are particularly common in insects (Vahed, 1998). Such gifts are either of exogenous (such as captured prey) or endogenous (i.e. manufactured by the males) origin (Lewis \& South, 2012; Lewis etal., 2014). Bushcricket males (Insecta: Orthoptera: Tettigoniidae) add endogenously derived material (called the spermatophylax) around the sperm-containing

Correspondence: Gerlind U. C. Lehmann, Department of Biology, Humboldt University Berlin, Invalidenstrasse 43, 10115 Berlin, Germany. Tel.: +49302093 9006; e-mail: gerlind.lehmann@t-online.de ampulla; the spermatophylax and ampulla combined are called the spermatophore. Immediately after copulation, the females start to consume the spermatophylax (Lehmann, 2012). It is well established that the spermatophylax acts as sperm protection device, deterring the female from removing or eating the ampulla during sperm transfer (Gwynne, 1997).

There is long-lasting debate about the other functions of the bushcricket spermatophore (Vahed, 2007; Gwynne, 2008; Lehmann, 2012) and this is hindered by limited knowledge concerning spermatophore composition. The spermatophore is obviously a food source for the female. Radioactive labelling shows that traces of male-provided material are slowly incorporated into newly manufactured eggs (Bowen etal., 1984; Gwynne, 1988; Wedell, 1993). In some herbivorous Phaneropteridae, female bushcrickets use the spermatophylax as a fast uptake food source, replacing plant feeding in the first $12 \mathrm{~h}$ after mating (Lehmann \& Lehmann, 2016) and male-derived carbohydrates rapidly contribute to their 
metabolism (Voigt et al., 2008). When food-deprived, females of several species increase mating rates (Gwynne, 2001) and compete for gift-giving males (Gwynne et al., 1998). Even females of an obligate parthenogenetic species accept heterospecific males for mating and consume the spermatophylax (Lehmann etal., 2011). The spermatophore can represent an important nitrogen resource for bushcrickets (Bowen etal., 1984; Wedell \& Ritchie, 2004), especially for species that rely on plants poor in nitrogen (Whitman et al., 1994; Awmack \& Leather, 2002). In a herbivorous bushcricket (Voigt et al., 2006), male-manufactured nitrogen transferred in the spermatophore is incorporated into female muscles after feeding. In female bushcrickets, female postmating responses are known that may increase the number or weight of eggs laid, delay remating for several days, lead to an earlier death (Lehmann, 2012) or alter food intake (Lehmann \& Lehmann, 2016). However, relatively little is known about the proteins in the spermatophore. One proposed function is the ability of the male to affect female behaviour through chemical manipulations (Gwynne, 2008), although this still lacks experimental support.

Recent studies propose the application of proteomics to the field of evolutionary ecology (Diz et al., 2012; Baer \& Millar, 2016) and behavioural ecology (Valcu \& Kempenaers, 2015). The main reason for this is that the proteome is closer to the phenotype than the genome and so it might be more relevant for identifying functional correlations and hence help with our understanding of the underlying natural selection and adaptation. Internal fertilizing animals are known for the transfer of seminal fluids along with the sperm cells during mating. These seminal fluids are produced in accessory glands (Gillott, 2003; Poiani, 2006) and are rich in seminal fluid proteins (SFP). Such SFPs are found in the ejaculate of several insect species (Avila et al., 2011). Accordingly, in the present study, we investigate the protein composition of the complex bushcricket spermatophore.

An understanding of the functional significance of the spermatophore is hindered by the limited knowledge about the content of the spermatophylax. As expected, water is the major component of the spermatophore (Bowen et al., 1984; Gwynne, 1988; Wedell \& Ritchie, 2004; Jarrige et al., 2015). Specialized substances in the ampulla of a bushcricket are carotenoids (Heller etal., 2000), which are known to act as antioxidant substances that scavenge free radicals (Costantini et al., 2010), thereby potentially protecting the sperm from oxidative stress. Amino acids can also be recovered as free units, particularly glycine (Heller et al., 1998). In crickets, glycine is known to affect the gustatory response of the females, keeping them occupied with feeding, leading to the formulation of the 'Candymaker hypothesis' for the spermatophylax (Warwick et al., 2009). Glycine is not only the smallest, but also one of the cheapest amino acids to produce (Akashi \& Gojobori, 2002; Wagner, 2005; Heizer et al., 2011), making its use a cost effective way of enticing females to feed on the spermatophylax and detering them from premature removal of the sperm containing ampulla.

Little is known about the proteins involved that make up the most of the spermatophore dry mass (Heller et al., 1998). Previous studies report proteins being found both in the sperm-containing ampulla and the spermatophylax (Heller etal., 1998; Marchini etal., 2009), although these studies employ low resolution one-dimensional gel electrophoreses and are unable to separate out individual proteins.

Systematically, the closest relatives of bushcrickets are crickets, for which we have knowledge of some protein content in the ejaculate of two species of the genus Allonemobius (Andrés et al., 2006, 2008; Braswell et al., 2006; Marshall et al., 2011) and Teleogryllus oceanicus (Simmons et al., 2013, 2014). However, crickets and bushcrickets are reported to have diverged from each other around 250 million years ago (Song etal., 2015). A key difference between bushcrickets and crickets is the presence of a spermatophylax in the majority of bushcrickets (Gwynne, 1995) and the general lack of such a spermatophylax in crickets, with a few exceptions, notably Gryllodes sigillatus, for which the spermatophylax but not the ampulla proteome is described (Pauchet et al., 2015). We still have a restricted knowledge of the protein composition in bushcricket spermatophores and especially for differences between protein patterns in the ampulla and the spermatophylax.

Based on their structure and function, protein types are very likely to differ between the ampulla and spermatophylax. Proteins transferred in the ampulla enter the female via a spermathecal duct, which leads to the spermatheca. A large proportion of these proteins may be involved in sperm transfer and consequently function to protect or maintain the male's sperm as in other insects (Avila et al., 2011). By contrast, the proteins of the spermatophylax are ingested by the females, entering the gut. This may allow females the possibility of digesting and breaking down male-derived proteins (Gwynne, 2008). Males might add protective proteins that have the capacity to counter this degrading effect, such as the serine protease inhibitor found in Gryllodes (Pauchet et al., 2015). A biochemical alternative for males would be to add prohormones, which are translated into the effector substance by female digestion.

The 'cost minimization principle' suggests that species minimize the cost of protein biosynthesis (Seligmann, 2003; Heizer et al., 2011). Three aspects can be predicted to make proteins costly. First, proteins are made of amino acids, which contain a substantial amount of nitrogen as a result of the amino group. Nitrogen is a restricted source for many organisms, including the herbivore bushcricket investigated in the present study, because the nitrogen content of plants is much less than that of phytophagous insects (Awmack \& Leather, 2002; Chown $\&$ Nicolson, 2004). Furthermore, nitrogen limitation can alter macromolecular elemental composition and bias the concentration of proteins (Elser et al., 2011). Second, metabolic costs are higher for larger proteins simply because adding more amino acid requires more energy (Akashi \& Gojobori, 2002; Bragg \& Wagner, 2009; Smith \& Chapman, 2010). Third, protein diversity itself can be expected to be costly to maintain. A greater number of proteins generally requires more genes, and/or post-transcriptional modifications, increasing both structural complexity and energy requirements (Lynch \& Marinov, 2015; O'Brien et al., 2016).

The number of different proteins in the ampulla could be expected to be within the range found in other insects (Avila etal., 2011; South etal., 2011; Boes etal., 2014; Scolari et al., 2016). By contrast, based on the cost assumptions and our 
knowledge of the bushcricket spermatophore (Lehmann, 2012), we provide two alternative hypotheses for protein numbers and protein diversity in the bushcricket spermatophylax:

The first hypothesis comprises 'the cheap spermatophylax hypothesis'. If the bushcricket spermatophylax exists to protect the ampulla and deter females from removing it until successful sperm transfer, then males may be selected to produce the cheapest spermatophylax possible. Under such a cost reduction scenario, we might expect the spermatophylax to have low protein diversity, as well as more proteins with smaller mass.

The second hypothesis comprises 'the expensive spermatophylax hypothesis'. Here, if the spermatophylax also helps to chemically influence female behaviour to favour the male's fitness, we can expect many different proteins, including those of high molecular mass, in the spermatophylax.

The present study aims to test these two hypotheses by examining protein composition and diversity of the spermatophore in a bushcricket.

\section{Materials and methods}

\section{Bushcrickets}

For the experiments, the herbivorous bushcricket species Poecilimon ampliatus (BRUNNER VON WATTENWYL, 1878) was used. The genus Poecilimon has several species that are well studied for evolutionary and ecological questions. Our study species has a moderately large spermatophore (G. U. C. Lehmann \& A. W. Lehmann, unpublished data) and is well studied with respect to acoustic ecology (Lehmann etal., 2007; Strauß et al., 2012, 2014) and spermatophore investment (Lehmann \& Lehmann, 2016).

In June 2014, 200 individuals were caught as nymphs in Slovenia (Gabrče $45^{\circ} 32^{\prime} \mathrm{N}, 13^{\circ} 58^{\prime} \mathrm{E}$ ). All animals were transferred to the laboratory at the Humboldt University Berlin, Germany and individually housed in $175-\mathrm{mL}$ transparent plastic vials (Drosophila rearing boxes; Greiner Bio-one $\mathrm{GmbH}$, Germany; www.GreinerBioone.com). We maintained their natural light/dark photocycle LD $14: 10 \mathrm{~h}$ and normal habitat temperature $\left(22^{\circ} \mathrm{C}\right)$. They were provided with an ad libitum food mixture of Taraxacum leaves and flowers and bee pollen from a healthfood store.

\section{Mating experiments to obtain probes}

After reaching sexual maturity, 10 males and 10 females were paired for mating in gauze cages. Because relative spermatophore mass varies with male age (Lehmann \& Lehmann, 2009; G. U. C. Lehmann \& A. W. Lehmann, unpublished data for $P$. ampliatus), we used males of either 5, 7, 11 or 13 days after the final moult. Matings were observed and the spermatophore from each of the 10 matings was removed from females using forceps immediately after attachment. Both components of the spermatophore were separated with forceps, stored individually in cryotubes and immediately frozen using dry ice (at $-80^{\circ} \mathrm{C}$ ).
Sample preparation and two-dimensional gel electrophoresis (2-DE) of spermatophylax and ampulla proteins

From the 10 matings, we selected four spermatophylaces and ampullae for 2-DE, representing each one male of either 5, 7, 11 or 13 days of age. Six volumes of sample preparation buffer (6 $\mathrm{m}$ urea, $3 \mathrm{~m}$ thiourea, $70 \mathrm{~mm}$ dithiothreitol) were added to the four individual spermatophylaces or ampullae, followed by five freeze/thaw cycles. After incubation for $30 \mathrm{~min}$ at room temperature, samples were centrifuged for $45 \mathrm{~min}$ at $15000 \mathrm{~g}$ and the supernatant was used for determination of the protein concentration (Bradford, 1976).

The Proteome Factory (Berlin, Germany) performed 2-DE based on the technique of Klose \& Kobalz (1995). For the analysis, $100 \mu \mathrm{g}$ of protein was mixed with $2 \%$ ampholytes $(\mathrm{pH} 2-11)$ and applied to vertical rod gels (9 м urea, $4 \%$ acrylamide, $0.3 \%$ piperazine diacrylamide, $5 \%$ glycerol, $0.06 \%$ $N, N, N^{\prime}, N^{\prime}$-tetramethylethane-1,2-diamine (TEMED) and $4 \%$ carrier ampholytes ( $\mathrm{pH} 2-11), 0.02 \%$ ammonium persulphate) for isoelectric focusing at $8820 \mathrm{Vh}$ in the first dimension. After focusing, the isoelectric focused (IEF) gels were incubated in equilibration buffer, containing $125 \mathrm{~mm}$ Tris/phosphate (pH 6.8), 40\% glycerol, $65 \mathrm{~mm}$ dithiothreitol and 3\% sodium dodecyl sulphate (SDS) for $10 \mathrm{~min}$ and subsequently frozen at $-80^{\circ} \mathrm{C}$. The second dimension SDS-polyacrylamide gel electrophoresis (PAGE) $(23 \times 30 \times 0.1 \mathrm{~cm})$ comprised $375 \mathrm{~mm}$ Tris/HCl buffer ( $\mathrm{pH} 8.8), 15 \%$ acrylamide, $0.2 \%$ bisacrylamide, $0.1 \%$ SDS and $0.03 \%$ TEMED. After thawing, the equilibrated IEF gels were immediately applied to SDS-PAGE gels. Electrophoresis was performed using $140 \mathrm{~mA}$ for $5.5 \mathrm{~h}$ until the front reached the end of the gel. After 2-DE separation, the gels were stained with FireSilver (PS2001; Proteome Factory, Germany) or with Periodic acid-Schiff staining (Zacharius et al., 1969; Kapitany \& Zebrowski, 1973). The fixed and $3 \times$ distilled water washed gel was treated with oxidizing reagent ( $1 \%$ periodic acid in $3 \%$ acetic acid for $50 \mathrm{~min}$ ) and subsequently washed six times with water. The gel was then stained with Schiff's reagent for $50 \mathrm{~min}$ and the staining was stabilized with $0.75 \%$ metasulphite in $10 \mathrm{~mm} \mathrm{HCl}$ for $1 \mathrm{~h}$, followed by three washes in water.

\section{Protein identification by liquid chromatography (LC)/mass spectrometry (MS)}

Protein identification using nano-LC-electrospray ionization (ESI)-tandem MS (MS/MS) was performed by the Proteome Factory. To prepare the samples for the MS experiments, protein spots (from the four 2-DE gels) or protein preparation in urea from the remaining six spermatophores were utilized. Spots were shrunk/swollen in $60 \%$ acetonitrile (ACN) w/50 mm triethylammonium bicarbonate (TEAB)/100 mM TEAB buffer in three cycles for $20 \mathrm{~min}$ each. During swelling of the spots, reduction of disulphide was performed by the addition of $5 \mathrm{~mm}$ tris(2-carboxyethyl)phosphine (TCEP) and subsequent alkylation by the addition of $10 \mathrm{~mm}$ iodoacetamide (IAA) in the dark. Proteins in urea were reduced by addition of $5 \mathrm{~mm}$ TCEP for $20 \mathrm{~min}$ and then $10 \mathrm{~mm}$ IAA was added to alkylate the liberated cysteine residues in a dark environment. For the spots, 
$200 \mathrm{ng}$ of trypsin in $20 \mu \mathrm{L}$ of $10 \% \mathrm{ACN}$ in $50 \mathrm{~mm}$ TEAB was used for in-gel proteolysis overnight at $35^{\circ} \mathrm{C}$. After proteolysis, peptides were acidified by the addition of 0.5 volumes of $2 \%$ formic acid (FA), resulting in $6.6 \% \mathrm{ACN}$ and $0.6 \%$ FA.

The MS system consisted of an Agilent 1100 nanoLC system (Agilent, Germany), PicoTip electrospray emitter (New Objective, Woburn, Massachusetts) and an Orbitrap XL or LTQ-FT Ultra mass spectrometer (ThermoFisher, Germany). Acidified peptides from a single spot were applied to nano-LC-ESI-MS/MS. Peptides were trapped and desalted on an enrichment column (Zorbax SB C18, $0.3 \times 5 \mathrm{~mm}$; Agilent) for $5 \mathrm{~min}$ using $2.5 \% \mathrm{ACN} / 0.5 \%$ formic acid as eluent, and then peptides were separated on a Zorbax $300 \mathrm{SB}$ $\mathrm{C} 18,75 \mu \mathrm{m} \times 150 \mathrm{~mm}$ column (Agilent) using an $\mathrm{ACN} / 0.1 \%$ formic acid gradient from $5 \%$ to $35 \%$ ACN within $40 \mathrm{~min}$. MS/MS spectra were recorded data-dependently by the mass spectrometer in accordance with the manufacturer's instructions. Identification of proteins was performed by an MS/MS ion search with the Mascot search engine (Matrix Science, U.K.). The ion charge in the search parameters for ions from ESI-MS/MS data acquisition was set to $1+, 2+$ or $3+$.

Further search parameters were: carbamidomethylation (fixed at $\mathrm{C}$ ), deamidation (variable at $\mathrm{N}$ or $\mathrm{Q}$ ) and oxidation (variable at $\mathrm{M}$ ). These parameters were chosen with respect to sample preparation and common modification events. Different types of databases were used in the experiments: the NCBInr database (https://www.ncbi.nlm.nih.gov/refseq) for undirected protein identification in various species and an NCBInr-derived Orthoptera database containing 21247 protein entries (January 2016) from various species. The Mascot search results were filtered by selecting $P<0.05$ and an ion score $>20$. Proteomic data of the tandem MS/MS search (raw data, peak lists and search files) are stored in accordance with the requirements of the ProteomeXchange Consortium (Vizcaíno etal., 2014) and documented in the jPOSTrepo (https://repository.jpostdb.org; Okuda et al., 2017) with the accession numbers: Ampulla spots 17, 18, 19: JPOSTID: JPST000190 PXID: PXD005024; Spermatophylax spots 1-16: JPOSTID: JPST000189 PXID: PXD005023. Ampulla Spots 9, 10, 11: JPOSTID: JPST000194 PXID: PXD005030; Ampulla liquid sample: JPOSTID: JPST000193 PXID: PXD005029: Spermatophylax liquid sample: JPOSTID: JPST000191 PXID: PXD005027.

\section{De novo sequencing with peaks}

Because neither the NCBInr database, nor the NCBInr-derived database contain actual bushcricket protein sequences, the identification had to rely on homologous sequences from other species, which could result in a failure to identify bushcricket proteins. To overcome this limitation, the MS datasets were used for de novo sequencing at a peptide level. The LC-MS/MS data files acquired in high resolution mode were used for analysis using PEAKS, version 7.5 (Bioinformatics Solutions Inc., Canada). The data refined parameters were: precursor correction, no additional filtering or merging of data. De novo parameters: parent mass error tolerance $3 \mathrm{ppm}$, fragment mass error tolerance $0.02 \mathrm{Da}$. The modifications selected were identical to the Mascot database searches. The NCBInr-derived Orthoptera database was used for error-tolerant de novo peptide matching. Peptide candidates with a calculated false discovery rate $<0.1 \%$ were taken into account.

\section{Results}

\section{Protein content}

A spermatophore of $P$. ampliatus contains (mean $\pm \mathrm{SD}$ ) $5.17 \pm 1.34 \mathrm{mg}$ of protein $(n=4)$. Within the spermatophore, the nutritious spermatophylax has more than double the amount of protein $(3.57 \pm 0.67 \mathrm{mg}, n=4)$ than the ampulla $(1.60 \pm 0.91 \mathrm{mg})$. The fresh spermatophore mass was $93.33 \pm 23.50 \mathrm{mg}(n=4)$. From other probes of this species, we know that $85 \%$ of the spermatophore is water. The remaining $15 \%$ of the spermatophore comprises $14 \mathrm{mg}$ dry mass. Using this simple approximation, the $5.17 \mathrm{mg}$ of protein in a spermatophore can be calculated as comprising $36 \%$ of the dry mass. As such, the protein fraction forms a major part of the spermatophore dry mass. We did not detect an increase in protein content with male age for the spermatophylax. By contrast, the protein mass in the ampulla was higher in the 13 -day-old male $(2.93 \mathrm{mg})$ than in the remaining three ampulla of younger males (ranging from 0.93 to $1.45 \mathrm{mg}$ ).

\section{Two-dimensional electrophoresis to determine the protein composition of ampulla and spermatophylax}

The 2-DE analysis that we applied has a capacity to separate up to 5000 spots (Klose \& Kobalz, 1995). Both the ampulla and spermatophylax had complex protein compositions, with approximately 850 different protein spots in total. The protein composition differed remarkably between the ampulla and spermatophylax. The spot number was twice as high in the ampulla (number of spots: range 573-602 for four different males) compared with the spermatophylax (number of spots: range 285-312 for four different males) (Fig. 1).

Testing the four different males across the adult age range of 5-13 days revealed limited variation between individuals (Fig. 2). Different individuals produced similar results for both the ampulla and the spermatophylax in terms of spot number, location and size (Fig. 2). The size distributions of proteins show clear differences between the ampulla and the spermatophylax (Fig. 1). Approximately 50 spots had the same position within the ampulla and the spermatophylax 2-DE pattern, which may be indicative of the same protein. These common protein spots are restricted to the middle protein mass of $30-60 \mathrm{kDa}$, especially prominent around $40 \mathrm{kDa}$. The range of protein size in the ampulla is smaller, with mass varying between 20 and $120 \mathrm{kDa}$, compared with a range from under 14.5 to $130 \mathrm{kDa}$ in the spermatophylax. The distribution in the ampulla is relatively even, with a majority of spots found above 20 and below $65 \mathrm{kDa}$. By contrast, within the spermatophylax, several large spots are 


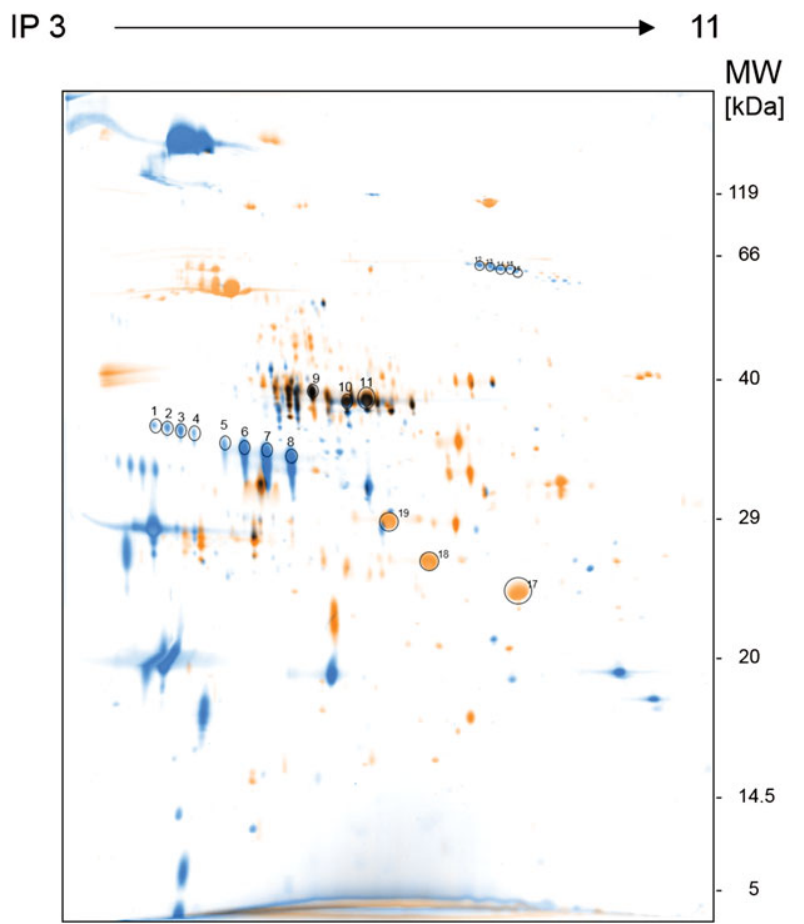

Fig. 1. Two-dimensional gel electrophoresis (2-DE) to separate the proteins of the spermatophore of the bushcricket Poecilimon ampliatus. The probes of the ampulla and the spermatophylax were analyzed independently. The probes were separated by isoelectric focusing in the first dimension on a $\mathrm{pH}$ gradient of 3-11 and in the second dimension by sodium dodecyl sulphate-polyacrylamide gel electrophoresis $(23 \mathrm{~cm} \times 30 \mathrm{~cm})$. After 2-DE separation, the gels were stained by FireSilver (PS2001; Proteome Factory). Molecular weight (kDa) is indicated at the right of the gel. The example shown represents an overlay of the ampulla and spermatophylax patterns of spermatophore number 8 . Protein spots found in the ampulla are orange, those in the spermatophylax are blue spots, and those recovered in both the ampulla and the spermatophylax are black spots. Circled and numbered spots were used in the attempts to identify the proteins. [Colour figure can be viewed at wileyonlinelibrary.com].

exclusively found below $14.5 \mathrm{kDa}$ and a very large protein is prominent at $130 \mathrm{kDa}$.

Attempts to identify proteins with mass spectrometry in 19 isolated spots from a 2-DE gel (for spot location, see Fig. 1) and in the total protein fraction were not successful. The Mascot searches and Peaks investigations were dominated by the identification of keratins, which are not known to be present in insects.

However, the reproducibility of the protein spot patterns from independent preparations from four different males (Fig. 2) reduces the probability of contamination as a cause for the spots. One explanation is that the digestion of the proteins was hindered by glycosylation and other post-translational modifications. Indeed, we confirmed post-translational modifications using glycostaining by identifying a great overlap between original protein spots and glycosylated protein spots within a bushcricket spermatophylax (Fig. 3).

\section{Discussion}

\section{Protein diversity in the ampulla and the spermatophylax}

We find a large number of putative proteins in both the ampulla and the spermatophylax, many more than reported for other species of insects. The number of approximately 600 protein spots in the ampulla is higher than the $38-280$ proteins detected in the ejaculate of other insect species (Avila et al., 2011; South et al., 2011; Boes et al., 2014; Scolari et al., 2016). Because methods vary in accuracy, the results might be not fully comparable with respect to the number of detected SFPs. Nonetheless, even with identical methods, the number of SFPs varies between 116 and 146 in three species of the genus Drosophila (Findlay etal., 2008, 2009), indicating that protein number might be a rapidly evolving character. The approximately 300 proteins in the spermatophylax is an order of magnitude larger than the 30 proteins detected in the spermatophylax of the cricket Gryllodes sigillatus (Pauchet etal., 2015).

An obvious feature from the 2-DE gels is that many of the putative proteins form a series of horizontal oriented spots. This might be indicative of protein speciation, caused by post-translational modifications at the same translated protein (Jungblut etal., 1996). It is worth noting that such protein speciation cannot be detected in the genome, transcriptome or the bottom-up analyzed proteome. Taking protein speciation into account and tentatively assigning spots lined horizontally on the 2-DE gels to one canonical protein, the number of genes coding for proteins in the $P$. ampliatus spermatophore compartments can be estimated to be one-quarter of the spot numbers: approximately 100 in the ampulla and more than 50 in the spermatophylax. With lower detection accuracy, these modifications might go unnoticed. Protein composition profiles are consistent between individuals (Fig. 2), regardless of the age of the adult, which varies from 5 to 13 days.

\section{Protein analysis}

Even though we are unable to identify the kind of proteins in the bushcricket spermatophylax, it is reasonable to postulate that many diverse protein functions will be presented by the high number of different proteins. Our stored data will allow the identification of the proteomes after a complete genome sequence and annotation becomes available for $P$. ampliatus or a related species. This will also allow the investigation of potential manipulative proteins in the ejaculate, as shown for some proteins in Drosophila (Avila et al., 2011).

Different protein species of the same protein may have different functions (Okkels etal., 2004; Lange etal., 2014) and different regulatory controls (Holland et al., 2011; Thiede et al., 2013). We provide clear evidence for glycosylation for many of the protein spots in the spermatophylax. Staining of glycoprotein is especially strong for the most intense spots on the 2-DE pattern, containing the largest amount of protein (Fig. 3). Glycosylation, comprising the binding of one or more sugar residues to the protein, is a common post-translational 


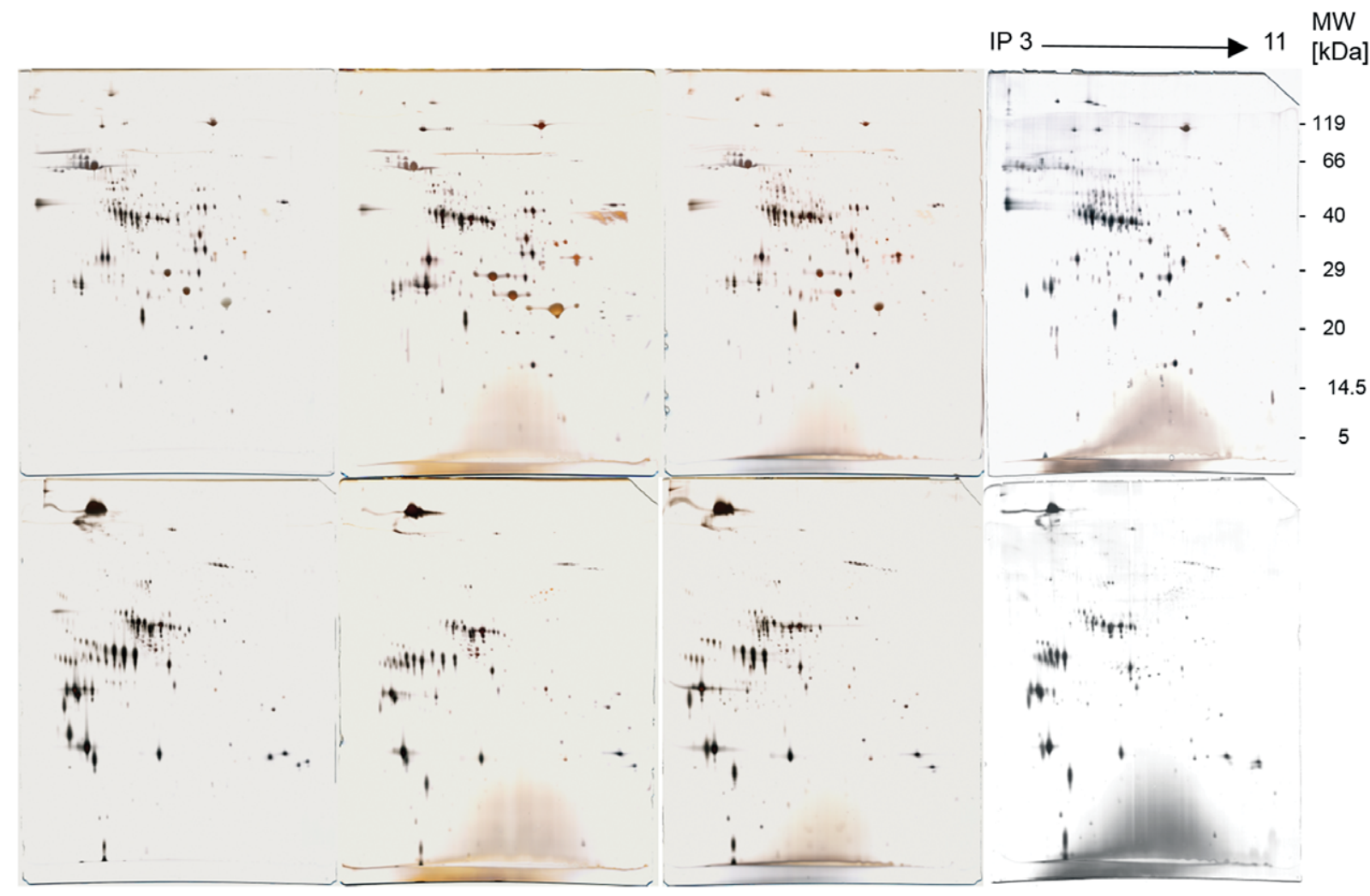

Fig. 2. Two-dimensional gel electrophoresis of ampulla (A1-A4, top) and spermatophylax ( $\mathrm{P} 1-\mathrm{P} 4$, bottom) from the four different individuals varying in age (male age: 13, 11, 7 and 5 days respectively). Gel size $23 \times 30 \mathrm{~cm}$. Proteins were stained with FireSilver (PS2001; Proteome Factory). [Colour figure can be viewed at wileyonlinelibrary.com].

modification, prominent in eukaryotes (Mann \& Jensen, 2003; Walsh et al., 2005), including insects (Vandenborre et al., 2011). Protein glycosylation is reported in almost every protein class. Common groups in which glycosylation occurs include the membrane and transmembrane proteins; however, this might not apply to the spermatophylax, which contains no cells. Other major classes of glycosylated proteins are ribosomal proteins and metabolic enzymes, such as dehydrogenases, proteases and amylases (Walsh etal., 2005). Proteases and amylases are of special interest: the first includes vitellogenin, an important glycoprotein for reproduction that is detected in most major insect lineages (Vandenborre et al., 2011; Tufail et al., 2014).

Another functionally highly significant class of proteins, often found to be glycosylated, is the class 'structural proteins'. Their inclusion would be important to stabilize the spermatophylax because it has a water content of approximately $80 \%$ (Heller et al., 1998; G. U. C. Lehmann \& A. W. Lehmann, unpublished data). This stabilizing function could also be accomplished by solutions of high-molecular weight glycoproteins that tend to be viscous and serve as lubricants, as in mucus (Li et al., 2008).

It is not surprising that the protein compositions vary greatly between spermatophylax and ampulla in the bushcricket P. ampliatus. The sperm-protecting spermatophylax has a very different function from the sperm-containing ampulla in bushcrickets (Lehmann, 2012). The spermatophylax contains twice the protein mass as the ampulla, whereas the number of types of proteins detected in the spermatophylax is around half of the number found in the ampulla. Protein sizes in the ampulla appears to be smaller than for the spermatophylax. This greater diversity of ampulla proteins is in line with the many different functions that it has to serve during sexual reproduction. Protein functions in ejaculates are known to be complex, supporting the transport and storage of sperm, protection from rival sperm, facilitation of egg-sperm interactions and changing female reproductive physiology (Pitnick etal., 2009; Avila etal., 2011). The spermatophylax has just two known main functions, protecting the ampulla from premature removal and influencing female postmating behaviour for the male's benefit. Therefore, the lower number of proteins in the spermatophylax may be reasonable given the more limited functions.

\section{Hypotheses for spermatophylax protein diversity}

Although the smaller number of protein spots in the spermatophylax compared with the ampulla in bushcrickets could be consistent with a 'cheap meal' function for the spermatophylax (Vahed, 2007; Gwynne, 2008), comparison with other insect data makes this less likely. The bushcricket spermatophylax appears to contain more types of proteins than the cricket spermatophylax (Pauchet etal., 2015). It also has as many or more types of proteins as are found in the ejaculates/ampulla of 


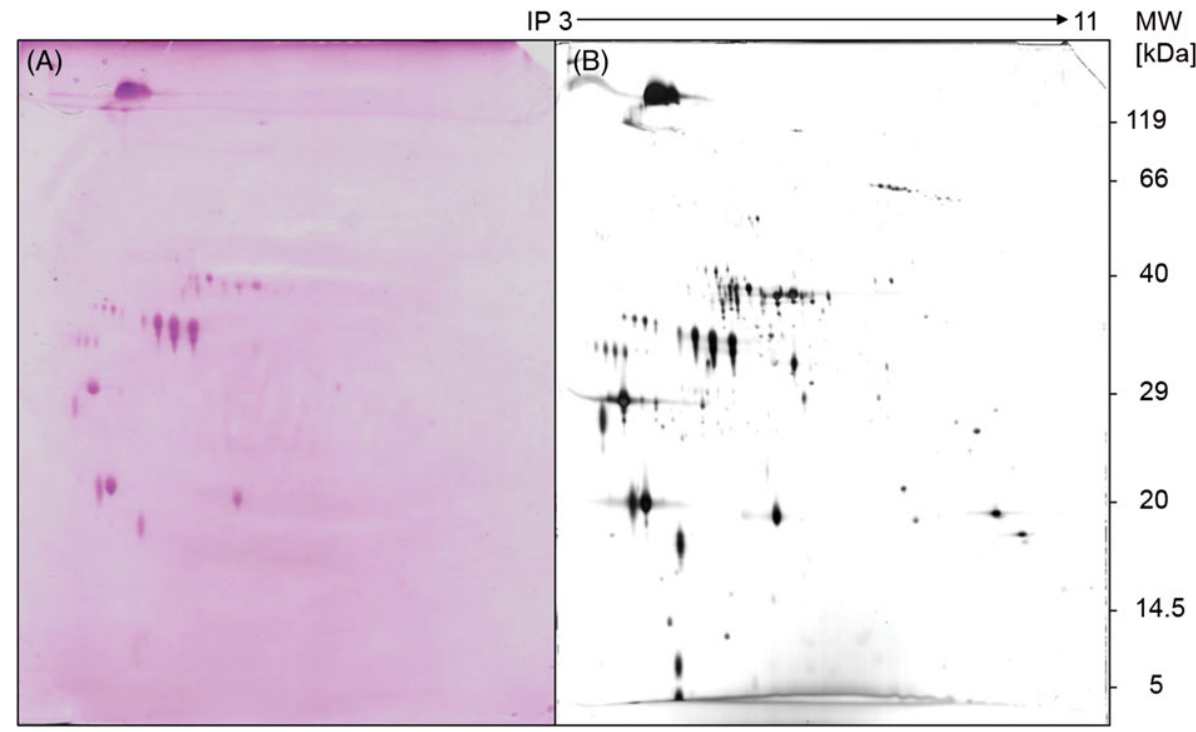

Fig. 3. Two-dimensional gel electrophoresis (2-DE) gel images of spermatophylax-derived proteins. (A) Glycoprotein-directed Periodic acid-Schiff staining of 2-DE gel. (B) The same sample after silver staining. [Colour figure can be viewed at wileyonlinelibrary.com].

other insect species (Avila et al., 2011). Furthermore, the diversification and size distribution of proteins in the spermatophylax is higher than expected, indicating that functions other than just structural integrity and the provision of a 'cheap meal' are involved. Even if protein diversity in the bushcricket spermatophylax is more a consequence of post-translational modifications rather than genomic diversity, this weakens support for the 'cheap spermatophylax hypothesis' because post-translational modifications also require significant metabolic energy investment (Seligmann, 2003; Heizer et al., 2011).

Currently, there is insufficient evidence to determine whether the expensive spermatophylax hypothesis fits the results. We have to wait until we are able to identify the detected proteins and especially understand their function. The pending sequencing of the complete genome of a bushcricket will help to improve protein identification of male-derived proteins. Nonetheless, the results of the present study are a promising addition to our understanding of the functional nature of male-female postmating interaction in bushcrickets, and demonstrate that their spermatophylax is neither a simple, nor a cheap 'gift'.

\section{Acknowledgements}

We thank Michael Reichert for helpful comments. Robert Hickson read and greatly improved the English in the final version of our manuscript submitted for publication. We thank three anonymous referees for their valuable comments. This work was supported by a research grant of the Ethologische Gesellschaft to GL. Conflicts of interest: three participants own (CS) or work for (KL, BN) the Proteome Factory, Berlin. This research company specializes in proteomics and holds patents for some of the methods used in the present study (FireSilver ${ }^{\circledR}$ ). The other three authors (GL, AL and PJ) declare that they have no conflict of interest.

\section{References}

Akashi, H. \& Gojobori, T. (2002) Metabolic efficiency and amino acid composition in the proteomes of Escherichia coli and Bacillus subtilis. Proceedings of the National Academy of Sciences of the United States of America, 99, 3695-3700.

Andrés, J.A., Maroja, L.S., Bogdanowicz, S.M. et al. (2006) Molecular evolution of seminal proteins in field crickets. Molecular Biology and Evolution, 23, 1574-1584.

Andrés, J.A., Maroja, L.S. \& Harrison, R.G. (2008) Searching for candidate speciation genes using a proteomic approach: seminal proteins in field crickets. Proceedings of the Royal Society of London Series B, 275, 1975-1983.

Avila, F.W., Sirot, L.K., LaFlamme, B.A. et al. (2011) Insect seminal fluid proteins: identification and function. Annual Review of Entomology, 56, 21-40.

Awmack, C.S. \& Leather, S.R. (2002) Host plant quality and fecundity in herbivorous insects. Annual Review of Entomology, 47, 817-844.

Baer, B. \& Millar, A.H. (2016) Proteomics in evolutionary ecology. Journal of Proteomics, 135, 4-11.

Boes, K.E., Ribeiro, J.M.C., Wong, A. et al. (2014) Identification and characterization of seminal fluid proteins in the asian tiger mosquito, Aedes albopictus. PLoS Neglected Tropical Diseases, 8, e2946.

Bowen, B., Codd, C. \& Gwynne, D.T. (1984) The katydid spermatophore (Orthoptera: Tettigoniidae): male nutrient investment and its fate in the mated female. Australian Journal of Zoology, 32, 23-31.

Bradford, M.M. (1976) A rapid and sensitive method for the quantization of microgram quantities of protein utilizing the principle of protein-dye binding. Analytical Biochemistry, 72, 248-254.

Bragg, J.G. \& Wagner, A. (2009) Protein material costs: single atoms can make an evolutionary difference. Trends in Genetics, 25, 5-8.

Braswell, W.E., Andrés, J.A., Maroja, L.S. et al. (2006) Identification and comparative analysis of accessory gland proteins in Orthoptera. Genome, 49, 1069-1080.

Chown, S.L. \& Nicolson, S. (2004) Insect Physiological Ecology: Mechanisms and Patterns. Oxford University Press, U.K.

Costantini, D., Rowe, M., Butler, M.W. \& McGraw, K.J. (2010) From molecules to living systems: historical and contemporary issues in 
oxidative stress and antioxidant ecology. Functional Ecology, 24, 950-959.

Diz, A.P., Martínez-Fernández, M. \& Rolán-Alvarez, E. (2012) Proteomics in evolutionary ecology: linking the genotype with the phenotype. Molecular Ecology, 21, 1060-1080.

Elser, J.J., Acquisti, C. \& Kumar, S. (2011) Stoichiogenomics: the evolutionary ecology of macromolecular elemental composition. Trends in Ecology \& Evolution, 26, 38-44.

Findlay, G.D., Yi, X., MacCoss, M.J. \& Swanson, W.J. (2008) Proteomics reveals novel Drosophila seminal fluid proteins transferred at mating. PLoS Biology, 6, e178.

Findlay, G.D., MacCoss, M.J. \& Swanson, W.J. (2009) Proteomic discovery of previously unannotated, rapidly evolving seminal fluid genes in Drosophila. Genome Research, 19, 886-896.

Gillott, C. (2003) Male accessory gland secretions: modulators of female reproductive physiology and behavior. Annual Review of Entomology, 48, 163-184.

Gwynne, D.T. (1988) Courtship feeding in katydids benefits the mating male's offspring. Behavioral Ecology and Sociobiology, 23, 373-377.

Gwynne, D.T. (1995) Phylogeny of the Ensifera (Orthoptera): a hypothesis supporting multiple origins of acoustical signalling, complex spermatophores and maternal care in crickets, katydids, and weta. Journal of Orthoptera Research, 4, 203-218.

Gwynne, D.T. (1997) The evolution of edible 'sperm sacs' and other forms of courtship feeding in crickets, katydids and their kin (Orthoptera: Ensifera). The Evolution of Mating Systems in Insects and Arachnids (ed. by J. Choe and B.J. Crespie), pp. 110-129. Cambridge University Press, Cambridge, Massachusetts.

Gwynne, D.T. (2001) Katydids and Bush-Crickets: Reproductive Behavior and Evolution of the Tettigoniidae. Cornell University Press, Ithaca, New York.

Gwynne, D.T. (2008) Sexual conflict over nuptial gifts in insects. Annual Review of Entomology, 53, 83-101.

Gwynne, D.T., Bailey, W.J. \& Annells, A. (1998) The sex in short supply for matings varies over small spatial scales in a katydid (Kawanaphila nartee, Orthoptera: Tettigoniidae). Behavioral Ecology and Sociobiology, 42, 157-162.

Heizer, E.M., Raymer, M.L. \& Krane, D.E. (2011) Amino acid biosynthetic cost and protein conservation. Journal of Molecular Evolution, 72, 466-473.

Heller, K.-G., Faltin, S., Fleischmann, P. \& von Helversen, O. (1998) The chemical composition of the spermatophore in some species of phaneropterid bush crickets (Orthoptera: Tettigonioidea). Journal of Insect Physiology, 44, 1001-1008.

Heller, K.-G., Fleischmann, P. \& Lutz-Röder, A. (2000) Carotenoids in the spermatophores of bushcrickets (Orthoptera: Ephippigerinae). Proceedings of the Royal Society of London B: Biological Sciences, 267, 1905-1908.

Holland, C., Schmid, M., Zimny-Arndt, U. et al. (2011) Quantitative phosphoproteomics reveals link between Helicobacter pylori infection and RNA splicing modulation in host cells. Proteomics, 11, $2798-2811$.

Jarrige, A., Body, M., Giron, D. et al. (2015) Amino acid composition of the bushcricket spermatophore and the function of courtship feeding: Variable composition suggests a dynamic role of the nuptial gift. Physiology \& Behavior, 151, 463-468.

Jungblut, P., Thiede, B., Zimny-Arndt, U. et al. (1996) Resolution power of two-dimensional electrophoresis and identification of proteins from gels. Electrophoresis, 17, 839-847.

Kapitany, R.A. \& Zebrowski, E.J. (1973) A high resolution PAS stain for polyacrylamide gel electrophoresis. Analytical Biochemistry, 56, $361-369$
Klose, J. \& Kobalz, U. (1995) Two-dimensional electrophoresis of proteins: An updated protocol and implications for a functional analysis of the genome. Electrophoresis, 16, 1034-1059.

Lange, S., Rosenkrands, I., Stein, R. et al. (2014) Analysis of protein species differentiation among mycobacterial low-Mr-secreted proteins by narrow $\mathrm{pH}$ range Immobiline gel 2-DE-MALDI-MS. Journal of Proteomics, 97, 235-244.

Lehmann, G.U.C. (2012) Weighing costs and benefits of mating in bushcrickets (Insecta: Orthoptera: Tettigoniidae), with an emphasis on nuptial gifts, protandry and mate density. Frontiers in Zoology, 9 , 19.

Lehmann, G.U.C. \& Lehmann, A.W. (2009) Condition-dependent spermatophore size is correlated with male's age in a bushcricket (Orthoptera: Phaneropteridae). Biological Journal of the Linnean Society, 96, 354-360.

Lehmann, G.U.C. \& Lehmann, A.W. (2016) Material benefit of mating: the bushcricket spermatophylax as a fast uptake nuptial gift. Animal Behaviour, 112, 267-271.

Lehmann, G.U.C., Strauß, J. \& Lakes-Harlan, R. (2007) Listening when there is no sexual signalling? - maintenance of hearing in the asexual bushcricket Poecilimon intermedius. Journal of Comparative Physiology A, 193, 537-545.

Lehmann, G.U.C., Siozios, S., Bourtzis, K. et al. (2011) Thelytokous parthenogenesis and the heterogeneous decay of mating behaviours in a bushcricket. Journal of Zoological Systematics and Evolutionary Research, 49, 102-109.

Lewis, S.M. \& South, A. (2012) The evolution of animal nuptial gifts. Advances in the Study of Behavior, 44, 53-97.

Lewis, S.M., Vahed, K., Koene, J.M. et al. (2014) Emerging issues in the evolution of animal nuptial gifts. Biology Letters, 10, 20140336.

Li, D., Huson, M.G. \& Graham, L.D. (2008) Proteinaceous adhesive secretions from insects, and in particular the egg attachment glue of Opodiphthera sp. moths. Archives of Insect Biochemistry and Physiology, 69, 85-105.

Lynch, M. \& Marinov, G.K. (2015) The bioenergetic costs of a gene. Proceedings of the National Academy of Sciences of the United States of America, 112, 15690-15695.

Mann, M. \& Jensen, O.N. (2003) Proteomic analysis of post-translational modifications. Nature Biotechnology, 21, 255-261.

Marchini, D., Brundo, M.V., Sottile, L. \& Viscuso, R. (2009) Structure of male accessory glands of Bolivarius siculus (Fischer) (Orthoptera, Tettigoniidae) and protein analysis of their secretions. Journal of Morphology, 270, 880-891.

Marshall, J.L., Huestis, D.L., Garcia, C. et al. (2011) Comparative proteomics uncovers the signature of natural selection acting on the ejaculate proteomes of two cricket species isolated by postmating, prezygotic phenotypes. Molecular Biology and Evolution, 28, 423-435.

O'Brien, E.J., Utrilla, J. \& Palsson, B.O. (2016) Quantification and classification of $E$. coli proteome utilization and unused protein costs across environments. PLoS Computational Biology, 12, e1004998.

Okkels, L.M., Müller, E.C., Schmid, M. et al. (2004) CFP10 discriminates between nonacetylated and acetylated ESAT-6 of Mycobacterium tuberculosis by differential interaction. Proteomics, 4, 2954-2960.

Okuda, S., Watanabe, Y., Moriya, Y. et al. (2017) jPOSTrepo: an international standard data repository for proteomes. Nucleic Acids Research, 45, D1107-D1111.

Pauchet, Y., Wielsch, N., Wilkinson, P.A. et al. (2015) What's in the Gift? Towards a molecular dissection of nuptial feeding in a cricket. PLOS ONE, 10, e0140191.

Pitnick, S., Wolfner, M.F. \& Suarez, S.S. (2009) Ejaculate-female and sperm-female interactions. Sperm Biology: An Evolutionary Perspective (ed. by T.R. Birkhead, D.J. Hosken and S. Pitnick), pp. 247-304. Academic Press, The Netherlands. 
Poiani, A. (2006) Complexity of seminal fluid: a review. Behavioral Ecology and Sociobiology, 60, 289-310.

Scolari, F., Benoit, J.B., Michalkova, V. et al. (2016) The spermatophore in Glossina morsitans morsitans: insights into male contributions to reproduction. Scientific Reports, 6, 20334.

Seligmann, H. (2003) Cost-minimization of amino acid usage. Journal of Molecular Evolution, 56, 151-161.

Simmons, L.W., Beveridge, M., Li, L. et al. (2014) Ontogenetic changes in seminal fluid gene expression and the protein composition of cricket seminal fluid. Evolution \& Development, 16, 101-109.

Simmons, L.W., Tan, Y.F. \& Millar, A.H. (2013) Sperm and seminal fluid proteomes of the field cricket Teleogryllus oceanicus: identification of novel proteins transferred to females at mating. Insect Molecular Biology, 22, 115-130.

Smith, D.R. \& Chapman, M.R. (2010) Economical evolution: microbes reduce the synthetic cost of extracellular proteins. MBio, 1, e00131-e00110.

Song, H., Amédégnato, C., Cigliano, M.M. et al. (2015) 300 million years of diversification: elucidating the patterns of orthopteran evolution based on comprehensive taxon and gene sampling. Cladistics, 31, 621-651.

South, A., Sirot, L.K. \& Lewis, S.M. (2011) Identification of predicted seminal fluid proteins in Tribolium castaneum. Insect Molecular Biology, 20, 447-456.

Strauß, J., Lehmann, G.U.C., Lehmann, A.W. \& Lakes-Harlan, R. (2012) Spatial organization of tettigoniid auditory receptors: insights from neuronal tracing. Journal of Morphology, 273, $1280-1290$

Strauß, J., Lehmann, G.U.C. \& Lehmann, A.W. (2014) Sensory evolution of hearing in tettigoniids with differing communication systems. Journal of Evolutionary Biology, 27, 200-213.

Thiede, B., Koehler, C.J., Strozynski, M. et al. (2013) High resolution quantitative proteomics of HeLa cells protein species using stable isotope labeling with amino acids in cell culture (SILAC), two-dimensional gel electrophoresis (2DE) and nano-liquid chromatography coupled to an LTQ-OrbitrapMass spectrometer. Molecular \& Cellular Proteomics, 12, 529-538.

Tufail, M., Nagaba, Y., Elgendy, A.M. \& Takeda, M. (2014) Regulation of vitellogenin genes in insects. Entomological Science, 17, $269-282$.
Vahed, K. (1998) The function of nuptial feeding in insects: a review of empirical studies. Biological Reviews, 73, 43-78.

Vahed, K. (2007) All that glisters is not gold: sensory bias, sexual conflict and nuptial feeding in insects and spiders. Ethology, 113, 105-127.

Valcu, C.M. \& Kempenaers, B. (2015) Proteomics in behavioral ecology. Behavioral Ecology, 26, 1-15.

Vandenborre, G., Smagghe, G., Ghesquière, B. et al. (2011) Diversity in protein glycosylation among insect species. PLOS ONE, 6, e16682.

Vizcaíno, J.A., Deutsch, E.W., Wang, R. et al. (2014) ProteomeXchange provides globally co-ordinated proteomics data submission and dissemination. Nature Biotechnology, 32, 223-226.

Voigt, C.C., Lehmann, G.U.C., Michener, R.H. \& Joachimski, M.M. (2006) Nuptial feeding is reflected in tissue nitrogen isotope ratios of female katydids. Functional Ecology, 20, 656-661.

Voigt, C.C., Kretzschmar, A.S., Speakman, J.R. \& Lehmann, G.U.C. (2008) Female bushcrickets fuel their metabolism with male nuptial gifts. Biology Letters, 4, 476-478.

Wagner, A. (2005) Energy constraints on the evolution of gene expression. Molecular Biology and Evolution, 22, 1365-1374.

Walsh, C.T., Garneau-Tsodikova, S. \& Gatto, G.J. (2005) Protein posttranslational modifications: the chemistry of proteome diversifications. Angewandte Chemie International Edition, 44, 7342-7372.

Warwick, S., Vahed, K., Raubenheimer, D. \& Simpson, S. (2009) Free amino acids as phagostimulants in cricket nuptial gifts: evidence for the 'Candymaker' hypothesis. Biology Letters, 5, 194-196.

Wedell, N. (1993) Spermatophore size in bushcrickets: comparative evidence for nuptial gifts as a sperm protection device. Evolution, 47, $1203-1212$

Wedell, N. \& Ritchie, M.G. (2004) Male age, mating status and nuptial gift quality in a bushcricket. Animal Behaviour, 67, 1059-1065.

Whitman, D.W., Blum, M.S. \& Slansky, F. Jr (1994) Carnivory in phytophagous insects. Functional dynamics of phytophagous insects (ed. by T.N. Ananthakrishnan), pp. 161-205. Oxford \& IBH Publishing, India.

Zacharius, R.M., Zell, T.E., Morrison, J.H. \& Woodlock, J.J. (1969) Glycoprotein staining following electrophoresis on acrylamide gels. Analytical Biochemistry, 30, 148-152.

Accepted 20 July 2017

First published online 21 August 2017 